\title{
Research on the Coordinated Development of International Trade Ecology and Global Economy under the Background of Economic Transformation
}

\author{
Zhiqian Hang* \\ Department of Economics Trinity College Dublin, Dublin, Ireland \\ *Corresponding author: hangz@tcd.ie
}

\begin{abstract}
With my country's accession to the WTO, its status in the international arena has become higher and higher, and trade exchanges between countries have become closer, especially in the development of today's society, the revitalization of the country cannot be separated from the improvement of the economic level. The relationship between ecological international trade and the development of economic globalization is dialectical and unified. The two are contradictory and at the same time interact, and jointly promote the long-term development of the global economy. The relationship between the development of the global economy and the ecologicalization of international trade is unity of opposites. How to properly resolve the conflicts between the two, better realize the coordinated development of the ecologicalization of international trade and the economy, and achieve healthy and sustained economic growth? It is an important issue facing the development of global international trade. The article pointed out these contradictions and proposed corresponding improvement plans to promote the real coordinated development of the economy and the environment.
\end{abstract}

Keywords: Ecological international trade; coordinated global economic development; economic transition.

\section{Introduction}

My country's economic development in recent years has continued to improve, and people's living standards have also improved. However, in the context of this prosperity, a series of problems have gradually emerged, the most important of which is the continuous reduction of resources, and what is more serious is that some resources are non-renewable [1]. In the face of this severe situation, the international trade industry is also aware of the crisis, so it puts forward the concept of ecological development of international trade [2]. With the passage of time, people pay more and more attention to the ecological concept of international trade, but in this process, how to coordinate its relationship with economic development has become an urgent practical problem [3]. The ecologicalization of trade on an international scale means that in the activities of international economy and trade, follow the concept of economic sustainable development, based on the idea of constructing a good ecological environment, the principle of developing circular economy and implement it in actual economic activities to ensure The global economy, environment and population can achieve sustainable development [4].

In international trade, gradually combining environmental protection with it, green production and green consumption, and establishing a sustainable economic model has become the mainstream of Global trade. Ecological international trade, that is, green international trade, instills the principle of ecological environment protection into trade activities, gradually infiltrates into global economic development, and realizes the common and harmonious development of economy and environment [5]. At the same time of economic development, the contradiction between human and ecological development is becoming increasingly prominent. How to maintain the pull of international trade on economic growth, realize the ecology of international trade and the coordinated development of global economy has become an urgent practical problem to be solved in the development process of international trade [6]. Infiltrate and implement the principles of sustainable development, ecological environment construction, and circular economy into economic development, so as to realize the sustainable development of various resources such as the environment, economy, and population on 
a global scale. The ecologicalization of international trade is to instill the principle of ecological protection into trade activities, in order to achieve the harmonious development between economy and environment, and to effectively implement the sustainable development strategy [7].

\section{Development trend of international trade ecology.}

\subsection{Economic development accelerates the inequality of resources.}

While economic globalization promotes the stable economic development of all countries in the world, it also exacerbates the inequality of resource development among countries to a certain extent, making it difficult to achieve sustainable development of the global economy. In the process of economic development, at the expense of resources, there is a correct understanding and consideration of local differences. This makes it difficult to ensure the common development of the regional economy and the environment, and it is difficult to effectively implement sustainable development strategies. The overall situation of economic development, political system, national conditions of development, and economic development are not the same, and resource allocation is also unfair to a certain extent. This is also a realistic contradiction between the ecologicalization of international trade and global economic development. In the process of global economic development, the unfair contradiction of capital distribution mechanism is an important factor restricting the ecology of international trade. In some special cases, capital even tends to developing countries with low development level, but this is based on the sacrifice of some resources, which is not in line with the concept of ecology of international trade.

There is no irreconcilable fundamental contradiction between the ecology of international trade and the coordinated development of the global economy. However, the actual situation is different from pure theoretical research, because the economic development of many countries is based on resources and environment. Before there is no fundamental change in the economic development model, there are still some opposites between them [8]. Due to the differences in economic growth rate, scale and national conditions, there are great differences in human and material capital among countries all over the world. It is precisely because of this difference that the allocation mechanism of resources among countries has changed due to its direct impact. The uneven distribution of resources was not considered in the later stage of economic development. The same speed of economic development will aggravate this imbalance, and then increase the gap of per capita resource possession. In response to this, many developing countries are very helpless. Therefore, in this case, there is no market to talk about the ecologicalization of trade and the coordinated development of the economy.

\subsection{Unfair distribution of capital brought about by economic development}

According to the different national conditions of each country, the economic development and scale are different. Therefore, the human, material, and financial resources invested by different countries to improve the economic development are all showing an unfair phenomenon., Due to the different degrees of economic differences in various regions in actual economic activities, the economic and trade between developing and developed countries is one-sided. The developed countries transfer high energy-consuming and high-polluting industries to developing countries. As a result, the ecological environment of developing countries has gradually deteriorated and has gradually moved away from the goal of developing an ecological economy. Under normal circumstances, the level of productivity plays a decisive role in the flow of capital, and the higher the level of productivity, the stronger the capital [9]. Given that capital has its own profit-seeking and liquidity, and it always flows to places with higher levels of productivity, the party enjoying the absolute advantage will enjoy the profit. Due to the differences in the national conditions and economic scales of different countries, there are also certain gaps in human and material resources, etc. This gap affects the resource allocation mechanism between countries to a certain extent, such as the productivity level of developed countries. Relatively high, which also affects the country's 
intensive production to a certain extent, so that it has a cost advantage in the development of trade. To some extent, it makes countries dependent on resources and environmental services, resulting in the opposite result. China is one of the most populous countries in the world. Although China is rich in resources, the consumption of resources is relatively large. Therefore, there is an unequal trend between China and western developed countries, which will hinder the ecological environment in the long run.

\section{Countermeasure and suggestion}

\subsection{Optimize the coordinated development of international trade ecology and global economy}

Carrying out international trade exchanges is a trade situation gradually formed with the development of the times. International trade exchanges are becoming more and more frequent, which can effectively promote the further improvement of the national economic level. However, it is not difficult to see that the acceleration of economic development also highlights an important problem. The theme of the ecologicalization of international trade and the coordinated development of the global economy cannot be achieved in a short time. Therefore, it should be regarded as a long-term international development strategy, that is, through long-term gradual changes, slowly reducing economic development. The degree of dependence on natural resources to achieve the harmonious development of economy, nature and society. It is necessary to implement the management responsibility of the ecologicalization of international trade and the coordinated development of the global economy, and implement and implement the sustainable development between resource environmental protection and economic development.

Give full play to the active role of the World Trade Organization and regional organizations, coordinate the economic development of countries around the world, and implement their own development functions and coordination functions into the actual coordinated economic development. In the process of foreign trade management, relevant the legislative construction of the country has strengthened functional supervision. It is assumed that the technological progress of the final product production department conforms to the following functional model:

$$
\left\{\begin{array}{l}
g_{A}=\frac{d A}{A d t}=\alpha \\
A\left(t_{0}\right)=A_{0}
\end{array} \Rightarrow A_{t}=A_{0} e^{\alpha t}\right.
$$

The above formula shows that the production technology of the final product sector is a variable that maintains a long-term fixed growth level. Suppose there are N enterprises that produce intermediate products, and each enterprise can only choose one technology to produce one product. The production function of the intermediate product department is:

$$
x_{i}=K_{i}
$$

The formula indicates that every unit of commodity I produced by an enterprise will consume one unit of capital. If the commodity price is $p_{i}$, then the total income of the enterprise producing $\mathrm{i}$ commodity is $p_{i} x_{i}$.At the same time, it is assumed that the enterprise will consume environmental resources in the production process, and sorted according to the level of environmental resource consumption from low to high. The production level of environmental resources conforms to a function uniformly distributed in the interval $[0, v]$ : 


$$
S_{i}=-b_{i} x_{i i} b_{i}=v \frac{i}{M} \in\left[0_{i} v\right]_{i} v \in\left[0_{i} 1\right]
$$

The above formula shows that the process of producing i-type products will consume a corresponding scale of environmental resources, and the level of environmental resource consumption for each unit of product produced by different enterprises is also different. The production units of low-polluting enterprises consume relatively few environmental resources, while the production units of high-polluting enterprises consume relatively more resources.

Strengthening the relationship between society, the environment and the economy is the current focus, which in turn can promote the further development of the economy. Only by improving the corresponding laws and regulations and paying attention to policies can they be continuously improved in the development process. Of course, all countries must participate in it and strictly abide by the corresponding laws and regulations to ensure the implementation of the concept [10]. The current situation of exporting domestic polluted wastes to foreign countries should be severely punished. After all, the earth is a whole, and if the environment in other regions deteriorates, a series of toxic waste exports will also be generated.

\subsection{Follow the rules of ecological international trade and coordinated development of global economy.}

In the process of international trade, the role of laws and regulations is very obvious. Because the development of all things requires a gradual process, if you are eager to achieve success, you are likely to make behaviors that do not meet the requirements in this process. Especially in the process of economic development, there will be many temptations. If laws and regulations are not adopted for restraint, it is very likely to disrupt the market order due to wrong behaviors and have a certain impact on social development. We should actively follow the relevant rules of the ecological development of international trade and the coordinated development of the global economy, and actively and effectively alleviate the contradiction between the ecological development of international trade and the development of the global economy. First, proceed from the economic development level, life philosophy, basic national conditions, population size, and overall situation of resources and environment in different countries and regions, based on the actual situation of personal development, and fully respect the development differences between regions.

Assuming that all consumers in the whole society have the same consumption preferences, and consumers have a standard fixed elastic utility function in the infinite time domain, the consumer utility function can be expressed as:

$$
U_{\mathrm{it}}=\int_{0}^{\infty} \frac{C_{i t}-1}{1-\sigma} e^{-p t} d t \quad \sigma, \rho>0
$$

Among them: $U_{i}$ and $C_{i}$ are consumers' utility level and consumption level of enterprise i's products, $\rho$ is the consumer's subjective preference rate, $\sigma$ is the elasticity of marginal utility, $r$ is the rate of return on social capital, according to Ramsey's condition, The optimal consumer decision can be drawn:

$$
\mathrm{g}_{c}=\frac{C_{i}}{C_{i}}=\frac{r-\rho}{\sigma} \Rightarrow C_{i t}=C_{i}(0) e^{\frac{r-\rho}{\sigma} t}
$$

By means of agreement, clear requirements for the development of the environment and resources are made to ensure the effect of environmental protection in the development of international trade and fundamentally promote the development of ecological development. In order to reduce the impact of trade on the environment and fundamentally promote the sustainable development of the ecological 
environment, corresponding trade measures are gradually being formed, which also promotes the ecologicalization of trade law to a certain extent. Among international trade organizations, environmental protection has become a prerequisite for economic activities and the primary purpose of the trading system. The regulations of the trade organization clearly stipulate the ecology and environmental protection in the trade process, and adopt laws at different levels to impose restrictions on international trade, with the purpose of realizing the ecological development of international trade. For the fairness and justice of the international market, it is necessary to strengthen the construction of relevant systems. On the basis of not affecting the economic benefits between countries, a unified standard that conforms to the international market norms is formulated, and trade transactions are conducted in accordance with the corresponding standards, which can effectively reduce Necessary questions.

\section{Conclusions}

In the future development process, we should not only focus on the growth of economic benefits and neglect the protection of the ecology, because the development of the ecological environment is the basis of economic development, and the two are complementary and develop together. Realizing the ecologicalization of international trade and the coordinated development of the economy is an important trend in international economic activities and trade exchanges. The traditional extensive development model will not be conducive to the coordinated development of the economy and the environment, and will seriously endanger resources and the environment. This model of economic development is unsustainable and will eventually die out. If we do not change the previous extensive economic development model and continue to promote rapid economic development in accordance with this model, it will only cause resource depletion and deterioration of the ecological environment, and ultimately affect the economic development of all countries. To strengthen the ecologicalization of international trade and the coordinated development of the global economy, we must start with the formulation of strategic goals, compliance with rules, and implementation of management responsibilities, actively and effectively alleviate the contradiction between the ecologicalization of international trade and the global economy, and achieve the stable and long-term development of human society. The ecologicalization of trade and the realization of the coordinated development of the economy are the needs of the development of the times. Only countries continue to make efforts in ecological trade to form norms around the world, and promote the fruit economy on the basis of ensuring the ecological nature, and realize the economic, economic, Sound development of the environment and society.

\section{References}

[1] Lili Zhu. Study on the ecological international trade and the coordinated development of the global economy [J]. Journal of Hubei University of Economics: Humanities and Social Sciences Edition, 2016, 13(8):2.

[2] Li Chenhua. Ecological international trade and coordinated development of global economy [J]. Financial economy: the second half of 2018(6):2.

[3] Li Wanli, yu zhang, Wang Zhen. Research on the ecological strategic choice of China's international trade economy under the new situation [J]. Shanxi Youth, 2019(13):1.

[4] Jiang Yali. Building a 5G boutique network. Beijing Mobile practices 5G double speed action [J]. Communication World, 2020(30):1.

[5] Sun Meihua, Li Shijin, Sun Tingting, et al. Li Shijin's ecological account of classroom teaching reform of Chinese culture-her name is Ji Tongtong, a freshman of International Trade Class of Economics and Management Department [J]. Youth, 2018(15):1.

[6] Liu Xiaoyu. Ecological strategic choice of China's international trade economy under the new situation [J]. Modern business trade industry, 2018, 39(6):2. 
[7] Wei Yun. Discussion on the teaching and training mode of international trade major in colleges and universities based on niche theory-taking the " $3+1$ " talent training mode of a university in Guangxi as an example [J]. Reform and opening up, 2019(15):5.

[8] Wei Yun. Discussion on the teaching and training mode of international trade major in colleges and universities based on niche theory-taking the " $3+1 "$ talent training mode of a university in Guangxi as an example [J]. Reform and opening up, 2019(15).

[9] Shen Yujie. Discussion on the influence of "camp reform" on enterprises-Take Xiamen International Trade as an example [J]. Taxation, 2019(7):4.

[10] Luo Yijun. Key technical points of landscape landscaping construction design and maintenance [J]. Jiangxi Building Materials, 2016(9):2. 